\title{
Neural Response Suppression Predicts Repetition Priming of Spoken Words and Pseudowords
}

\author{
Eleni Orfanidou, William D. Marslen-Wilson, and Matthew H. Davis
}

\begin{abstract}
An important method for studying how the brain processes familiar stimuli is to present the same item on more than one occasion and measure how responses change with repetition. Here we use repetition priming in a sparse functional magnetic resonance imaging (fMRI) study to probe the neuroanatomical basis of spoken word recognition and the representations of spoken words that mediate repetition priming effects. Participants made lexical decisions to words and pseudowords spoken by a male or female voice that were presented twice, with half of the repetitions in a different voice. Behavioral and neural priming was observed for both words and pseudowords and was not affected by voice changes. The fMRI data revealed an elevated
\end{abstract}

\section{INTRODUCTION}

An important method for studying how the brain processes familiar stimuli is to present the same object or word on more than one occasion and observe how behavioral and neural responses are changed by repetition. This repetition priming technique has produced countless demonstrations of faster and more accurate behavioral responses for items that have been recently encountered. At the neural level, a common finding is that repeated stimulus presentation results in decreased neural activity as measured using positron emission tomography (PET) or functional magnetic resonance imaging (fMRI). Brain regions that are activated during the first presentation of a particular stimulus show a reduced response to second presentations (for a review, see Henson, 2003; Schacter \& Buckner, 1998).

Repetition priming can provide a direct means of testing how the brain converts sensory impressions into a stable representation of the important entities in the outside world. The rationale behind these studies is that if a brain region shows the same priming effect irrespective of changes to physical characteristics of the stimuli, such as size differences for visually presented objects (Vuilleumier, Henson, Driver, \& Dolan, 2002) or case differences for visually presented words (Dehaene,

MRC Cognition and Brain Sciences Unit, Cambridge, UK response to words compared to pseudowords in both posterior and anterior temporal regions, suggesting that both contribute to word recognition. Both reduced and elevated activation for second presentations (repetition suppression and enhancement) were observed in frontal and posterior regions. Correlations between behavioral priming and neural repetition suppression were observed in frontal regions, suggesting that repetition priming effects for spoken words reflect changes within systems involved in generating behavioral responses. Based on the current results, these processes are sufficiently abstract to display priming despite changes in the physical form of the stimulus and operate equivalently for words and pseudowords.

Naccache, Cohen, et al., 2001), then neural processes in this region can be inferred to operate over more abstract (view independent or case independent) representations. Recent priming studies have characterized a succession of neural processing stages by which an abstract representation of printed words is generated in the fusiform gyrus, independent of the case and retinal position of the constituent letters (Dehaene, Naccache, Ciuciu, et al., 2004; Dehaene, Naccache, Cohen, et al., 2001). Similarly, for visually presented objects and faces, fMRI studies using repetition priming have revealed a series of dissociable processing stages by which the sensory properties of visual stimuli are converted into more abstract representations, independent of viewpoint, surface texture and orientation (James, Humphrey, Gati, Menon, \& Goodale, 2002; Vuilleumier et al., 2002; Koutsaal et al., 2001; Kourtzi \& Kanwisher 2000; GrillSpector et al., 1999).

In the current work we apply a similar fMRI repetition priming technique to probe neural processes involved in the identification of spoken words. When applied to spoken word recognition, the approach adopted in neuroimaging studies of visual priming is challenged by a controversy concerning the role of abstract representations in spoken word recognition. Existing visual priming research is predicated on the assumption that progressively more abstract perceptual representations are generated by discarding irrelevant detail in the sensory input. However, research using 
spoken stimuli has revealed a number of situations in which specific, surface details of speech are retained and influence the processing of subsequent repetitions. For instance, behavioral studies have shown that changes to the voice used to produce first and second presentations can reduce the magnitude of repetition priming observed with spoken materials (McLennan \& Luce, 2005; Pilotti et al., 2000; Goldinger, 1996). These and other results showing the retention of surface detail for speech in episodic memory (Goldinger, 1998; Sheffert, 1998; Church \& Schacter, 1994; Palmeri, Goldinger, \& Pisoni, 1993; Schachter \& Church, 1992) challenge the idea that behavioral or neural priming of spoken words depends on representations that are sufficiently abstract as to exclude the surface details of speech (cf. "episodic" accounts of spoken word recognition [Goldinger 1996, 1998] that deny any role for abstract representations).

We can contrast these episodic accounts with more traditional, abstractionist accounts in which word recognition and repetition priming are both mediated by abstract representations that exclude the surface details of spoken words (e.g., Luce \& Pisoni, 1998; Norris, 1994). In assessing the neural basis of these diverse accounts of spoken word recognition, neuroimaging evidence concerning the systems that mediate repetition priming is highly relevant. For instance, if explicit memory, but not lexical/semantic representations, encode the surface detail of speech (see Luce \& Lyons, 1998) then we might observe different repetition priming profiles within neural systems involved in episodic memory and lexical processing.

A further issue in studying neural repetition priming for spoken words concerns the anatomical complexity of the auditory system. The ventral, object processing pathway in vision is well studied in macaques, and a hierarchy of processing stages has long been established for visual object processing in ventral occipital and temporal lobe regions (Ungerleider \& Mishkin, 1982). Evidence for hierarchical organization in fMRI studies of visual priming in humans therefore builds on, and is supported by, evidence from single-cell recordings in primates. However, similar homologies between macaque and man in the auditory domain are less clearly established. Recent evidence from macaques point to multiple processing pathways (dorsal and ventral) in the superior temporal lobe that receive input from the primary auditory cortex (Kaas \& Hackett, 2000; Rauschecker \& Tian, 2000; for a review, see Rauschecker, 1998). However, it remains unclear how these various pathways subserve complex linguistic functions in humans.

Recent functional neuroimaging studies provide evidence that speech perception is based on hierarchical processing pathways that radiate from the primary auditory cortex (Davis \& Johnsrude, 2003; Scott \& Johnsrude, 2003; Binder, Frost, Bellgowan, et al., 2000; Scott, Blank, Rosen, \& Wise, 2000) with abstraction from acoustic properties of speech at higher levels (Davis \& Johnsrude, 2003). However, the neural basis of auditory word recognition in humans has not been clearly established. Some researchers propose that a posterior, inferior temporal system plays a crucial role in word recognition (Hickok \& Poeppel, 2000, 2004), drawing on evidence from aphasic stroke patients that suggests a role for the posterior inferior temporal cortex in assigning meaning to speech (Bates et al., 2003). Others emphasize a role for anterior temporal regions in word identification (Scott \& Johnsrude, 2003), consistent with the location of auditory association cortex in macaques (Romanski et al., 1999) and supported by the semantic deficits that follow anterior temporal lobe damage in humans with semantic dementia (e.g., Chan et al., 2001; Galton et al., 2001; Mummery et al., 1999). In the light of these disagreements, a further goal of the present study was therefore to use neural repetition priming to explore the functional role of anterior and posterior temporal systems in spoken word recognition.

One illustration of how neural repetition priming can be used to identify systems critical for the recognition of familiar stimuli comes from the literature on face perception. Neuroimaging studies from Henson and colleagues (Eger, Schweinberger, Dolan, \& Henson, 2005; Rothstein, Henson, Treves, Driver, \& Dolan, 2004; Henson, Price, Rugg, Turner \& Friston, 2002; Henson, Shallice, \& Dolan, 2000) have highlighted a number of regions of the temporal lobe that show neural priming for repetitions of familiar faces but not for unfamiliar faces, particularly when different views of the same face are repeated (Eger et al., 2005; Rothstein et al., 2004). These findings suggest that abstract representations of facial identity, independent of the physical stimulus, are encoded in ventral, anterior temporal regions that show interactions between familiarity and priming. A similar interaction has recently been shown for written words, with priming observed for familiar words but not for unfamiliar pseudowords in the left fusiform gyrus (Fiebach, Gruber, \& Supp, 2005). In the context of spoken word recognition, these findings suggest that comparing neural priming for familiar words and unfamiliar pseudowords may provide a means of isolating the neural systems critical for word recognition. In the behavioral literature, the presence or absence of priming for unfamiliar pseudowords is a topic of debate (for reviews, see Bowers, 2000; Tenpenny, 1995). There is agreement, however, that for the lexical decision task, greater priming is observed for real words (see McKone \& Dennis. 2000; Mimura, Verfaellie, \& Milberg, 1997; Bowers, 1996; Brown \& Carr, 1993; Duchek \& Neely, 1989; Ratcliff, Hockley, \& McKoon, 1985), although results for perceptual identification and naming are more mixed (e.g., Brown \& Carr, 1993; Rueckl, 1990; Feustel, Shiffrin, \& Salasoo, 1983).

The present study therefore uses fMRI to assess the neural systems activated in response to spoken words 
and pseudowords, and evaluates how neural responses change with repetitions of either the physically identical stimulus, or a recording of the same item produced by a different speaker. By analogy to prior investigations of face recognition and priming, this design will allow us to assess whether the brain regions that show repetition priming are engaged in abstract perceptual processing of familiar items. However, for spoken word recognition, overlap between repetition priming effects and regions involved in encoding and retrieving specific episodic memories of prior encounters are also of interest. Previous neuroimaging studies of spoken word priming using stem completion or word generation have found reduced activity for repeated word presentations in left inferior frontal regions and inferior temporal regions (Buckner, Koutstaal, Schacter, \& Rosen, 2000). However, repetition-related reductions have not been observed in auditory regions for word stimuli (Badgaiyan, Schacter, \& Alpert, 2001; Wagner, Koutsaal, Maril, Schacter, \& Buckner, 2000; although see Bergerbest, Ghahremani, \& Gabrieli, 2004, for a study using environmental sounds). Priming effects observed for these "generation" tasks (such as stem completion) may not be comparable to the perceptual tasks commonly used in behavioral studies of spoken word recognition and in comparable fMRI studies of face perception. In the current work, our primary interest was in priming effects that reflect neural processes involved in spoken word recognition rather than response generation. However, it is not clear that fMRI repetition priming provides an unambiguous measure of these perceptual processes (Dobbins, Schnyer, Verfaellie, \& Schacter, 2004). We address this possibility by conducting correlation analyses to assess which repetition-related neural changes are most predictive of the magnitude of behavioral priming in single trials.

\section{METHODS}

The current fMRI study used an event-related, sparseimaging design with a factorial crossing of three variables: lexicality (words vs. pseudowords), repetition (first vs. second presentations), and voice (some stimuli were repeated in the same or different voice to initial presentations). Repetitions occurred after approximately 12 intervening items ( 30 -sec delay). Participants were required to make a lexical decision (real vs. pseudoword) to each item.

\section{Participants}

Thirteen participants ( 7 women) took part in the fMRI study. All were right-handed, native speakers of English between the ages of 18 and 40 years. All participants gave informed consent after the experimental procedure was explained.

\section{Stimuli}

The stimulus set consisted of 240 low-frequency words (monosyllabic and bisyllabic concrete nouns) and 240 pseudowords, divided into eight groups matched on a number of variables (length in phonemes and syllables, bigram/trigram frequency, uniqueness/deviation point, and for the words, imageability and CELEX frequency; Baayen, Piepenbrock, \& van Rijn, 1993). An analysis of variance (ANOVA), in which group was entered as the fixed factor and each of these variables as the dependent measure, revealed no significant differences between the groups $\left(F_{S}<1\right)$. The stimuli in four groups $(\mathrm{a}-\mathrm{d})$ were treated as the test items and presented twice, whereas those of the remaining four groups $(\mathrm{e}-\mathrm{h})$ were used as fillers and presented only once. The stimuli were recorded on digital audio tape (DAT) in a soundproof booth by both a male and a female native English speaker at a sampling rate of $44.1 \mathrm{kHz}$ and edited into separate files for playback using Cool Edit software, Syntrillium Software Corp., Phoenix, AZ. The recorded stimuli were checked by a phonetician for any differences in pronunciation between the two speakers to avoid confounds between phonetic variation and potential voice effects.

\section{Experimental Design}

The experimental design included 120 test words (concrete nouns, divided into four matched groups of 30 items) and 120 test pseudowords (also divided into four matched groups) each of which were presented twice. Half of all repetitions were in a "different voice" from the first presentations. To cancel out item-specific effects, the four groups of test items were pseudorandomly assigned to same voice and different voice repetitions for different volunteers, creating a four-version experiment. Repetitions occurred after approximately 12 intervening items ( 30-sec delay). In addition, 120 filler words and 120 pseudowords were added to the design (matched to the groups of test items on relevant psycholinguistic variables), each presented once to disguise stimulus repetition. This configuration resulted in 480 test trials and 240 filler trials, 720 trials overall. In addition to these test and filler trials, 240 null events (instances where no stimulus was presented) were used to provide a resting baseline, resulting in a total of 960 events in the experiment. These 960 events were divided into three sessions of 320 trials each. Stimuli were presented with a stimulus onset asynchrony of $2.506 \mathrm{sec}$, synchronized to alternate with the echo-planar imaging (EPI) acquisition. Each scanning session lasted approximately $13 \mathrm{~min}$.

\section{Behavioral Procedure and Analysis}

Each participant was given a brief practice session beforehand as well as a short practice block that included the 
rapid alternation of stimuli and scanner noise once in the scanner. This practice block was followed by the three 13-min scanning runs. The stimuli were presented auditorily over high-quality headphones (Resonance Technology, Commander XG system) using DMDX software running on a Windows PC (Forster \& Forster, 2003). Participants made lexical decision responses to each target on a custom button box held in their right hand by pressing a button under their index finger to indicate a word, or a button with their middle finger to indicate a pseudoword. Accuracy and reaction times (RTs, with millisecond accuracy, measured from word onset) were recorded. Accuracy feedback was given only in the practice blocks.

Incorrect responses were discarded from the RT analyses and mean response times and accuracy for each participant in each condition were calculated. Because stimuli were counterbalanced and different items were pseudorandomly assigned to different repetition conditions for different volunteers, ANOVA by items was not considered necessary (Raaijmakers, Schrijnemakers, \& Gremmen, 1999).

\section{fMRI Scanning Technique and Data Analysis}

Imaging was performed on a $3 \mathrm{~T}$ Bruker scanner using a head coil. Functional images were collected using 21 axial slices angled away from the eyes and covering most of the brain (slice thickness $4 \mathrm{~mm}$, interslice distance $1 \mathrm{~mm}$, matrix size $64 \times 64$, field of view $20 \times 20 \mathrm{~cm}$, in-plane resolution of approximately $3 \times 3 \mathrm{~mm}$ ) with an EPI sequence $(\mathrm{TR}=2.506 \mathrm{sec})$. To avoid interfering effects of scanner noise, we used bunched image acquisition in which a single volume $(\mathrm{TA}=1.1 \mathrm{sec})$ is acquired, followed by a silent period $(1.406 \mathrm{sec})$ during which a single stimulus item is presented. In each of three experimental sessions, 326 functional EPI images were acquired ( $\sim 13$ min scanning time per session). Six images at the start of each run were discarded to allow the EPI signal to reach equilibrium. Highresolution anatomical images (SPoiled GRass; SPGR) and field maps were also acquired for use in preprocessing and normalization.

Data were preprocessed and analyzed using Statistical Parametric Mapping software (SPM2, Wellcome Department of Cognitive Neurology, London, UK). Prior to analysis, all images were corrected for motion by realigning them with respect to the first image. A map of the magnetic field was acquired to correct for geometric distortions to the EPIs resulting from field inhomogeneities (Cusack, Brett, \& Osswald, 2003). The mean of the realigned, undistorted images was coregistered with the structural T1 volume, which was then spatially normalized to a standard template. The same spatial transformation was then applied to the realigned undistorted EPI volumes. Finally, the normalized images were smoothed with a 12 -mm full-width half-maximum
(FWHM) Gaussian kernel suitable for random-effects analysis (Xiong et al., 2000).

Data from each subject was entered into a general linear model using an event-related analysis procedure (Josephs \& Henson, 1999). Thirteen event types were modeled for each session (the factorial crossing of words/pseudowords, male/female voice, and first vs. second, same-voice vs. second, different-voice presentation). Filler (nonrepeated) items were included with first presentations and therefore contribute to relevant contrasts. An additional column coded trials on which participants made lexical decision errors. Each event was modeled using the canonical hemodynamic response function in SPM2 with temporal and dispersion derivatives to correct for changes in the latency and duration of the evoked blood oxygen level dependent (BOLD) response (Henson, Price, et al., 2002). Movement parameters estimated at the realignment stage of preprocessing were added as regressors of no interest. A high-pass filter (cutoff $128 \mathrm{sec}$ ) and AR1 correction for serial autocorrelation was applied. Contrasts of parameter estimates for the canonical hemodynamic response from single-subject models were entered into randomeffects analyses (one-sample $t$ tests) comparing the mean parameter estimate over subjects to zero. Significant results that pass both uncorrected $(p<.001)$ and whole-brain corrected (false discovery rate [FDR], $p<$ .05 , Genovese, Lazar, \& Nichols, 2002) thresholds are reported. By combining an uncorrected and corrected threshold we limit the effect of the adaptive FDR threshold that can otherwise produce a statistical threshold more lenient than $p<.001$ uncorrected (if a large number of voxels are active). In subsequent analysis, the magnitude of behavioral priming (i.e., the RT difference between first and second presentations) was added as a "parametric modulator" for second presentation trials (Buchel, Holmes, Rees, \& Friston, 1998). Parameter estimates for the effect of this modulator in each subject were entered into random-effects analysis comparing the mean effect of behavioral priming on neural responses to zero. For this follow-up analyses and other region-of-interest (ROI) analyses in the article we adopt a more lenient, although still corrected, threshold (uncorrected $p<.005$ and $p<.1$ FDR). In addition, we test for effects at peak voxels in orthogonal contrasts at an uncorrected threshold of $p<.05$. Given the degree of smoothing used in these analyses (12 mm FWHM), this procedure is equivalent to assessing the average response from a small, spherical ROI centered on the peak voxel.

\section{RESULTS \\ Behavioral Results}

Mean response times and error rates were $903 \mathrm{msec}$ and 9\% for words, 1009 msec and 11\% for pseudowords. 
Table 1. Mean RTs (Milliseconds) and Error Rates (Percentages)

\begin{tabular}{|c|c|c|c|c|c|c|c|c|}
\hline \multirow[b]{3}{*}{ Condition } & \multicolumn{4}{|c|}{ Words } & \multicolumn{4}{|c|}{ Pseudowords } \\
\hline & \multicolumn{2}{|c|}{ First Presentation } & \multicolumn{2}{|c|}{ Second Presentation } & \multicolumn{2}{|c|}{ First Presentation } & \multicolumn{2}{|c|}{ Second Presentation } \\
\hline & $R T$ & $E R$ & $R T$ & $E R$ & $R T$ & $E R$ & $R T$ & $E R$ \\
\hline $\mathrm{FF}$ & 935 & 0.08 & 868 & 0.06 & 1028 & 0.09 & 975 & 0.13 \\
\hline FM & 954 & 0.11 & 835 & 0.06 & 1036 & 0.09 & 964 & 0.09 \\
\hline MF & 913 & 0.07 & 852 & 0.06 & 1010 & 0.08 & 981 & 0.09 \\
\hline MM & 907 & 0.07 & 819 & 0.05 & 1001 & 0.10 & 932 & 0.11 \\
\hline
\end{tabular}

$\mathrm{FF}=$ female-female; $\mathrm{FM}=$ female-male; $\mathrm{MF} ;$ male-female; $\mathrm{MM}=$ male-male .

Table 1 displays means of the RTs for correct responses and error rates to words and pseudowords in each condition for first and second presentation. RTs to second occurrences were subtracted from RTs to the first, so a positive value indicates facilitation (see Figure 1). To directly compare the magnitude of priming for words and pseudowords in the same and different voice conditions, an ANOVA was performed on the priming scores. A main effect of lexicality, $F(1,12)=14.300$, $p<.003$, was found, with priming effects being more pronounced for words than for pseudowords, although priming effects for pseudowords were still reliable, $t(12)=7.384, p<.001$. There was no effect of voice on the magnitude of priming, either as a main effect, $F(1,12)=2.036, p<.179$, or as an interaction (Lexicality $\times$ Voice: $F<1$ ).

\section{Imaging Results}

The contrast of all word events compared to pseudoword events revealed reliable left-hemisphere activation

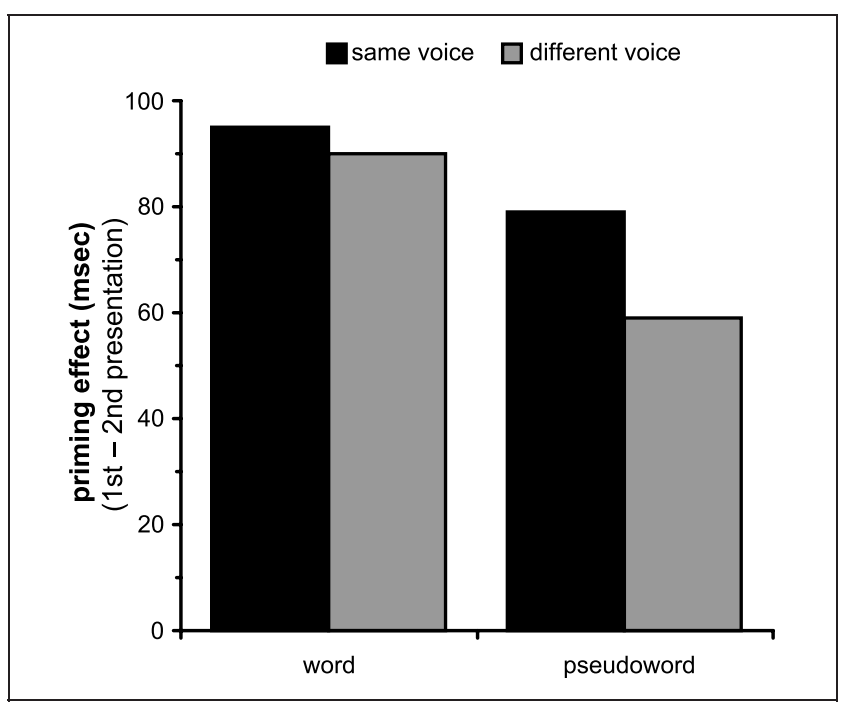

Figure 1. Behavioral results: repetition priming effects by condition (milliseconds). in frontal and temporal lobe regions known to be involved in lexical and semantic processing of real words (cf. Binder, Frost, Bellgowan, et al., 2000). In particular, activated regions included the supramarginal gyrus extending into the angular gyrus bilaterally, the anterior middle temporal gyrus (MTG) and the left anterior prefrontal cortex (see Table 2, Figure 2A, and Figure 3A). An activation cluster was also observed in the left posterior inferior temporal lobe, including a peak voxel in the anterior part of the fusiform gyrus. The reverse contrast (pseudowords vs. words) failed to show voxels that responded more to pseudowords than to words at a corrected level of significance.

In the context of this experiment and in the light of the behavioral data, a primary focus was the presence or absence of an interaction between lexicality and repetition. The relevant comparison between the repetition effect for words and the repetition effect for pseudowords did not reach a corrected level of significance in any voxel. Whole-brain analysis did not reveal any brain area that showed a greater repetition effect for real words (as in the behavioral data) or the reverse effect (a more pronounced repetition effect for pseudowords) at a corrected level. To ensure that this did not reflect a lack of sensitivity because whole-brain analyses are heavily corrected for multiple comparisons, we conducted two further ROI analyses. First, we tested for a lexicality by priming interaction within brain areas that show a lexicality effect by conducting an ROI analysis within the region more strongly activated for real words shown in Figure 2A. Again, there were no voxels within this ROI that showed a lexicality by priming interaction. Finally, to remove the need for correction for multiple comparisons, we extracted the parameter estimates for peak voxels that showed a lexicality effect (as listed in Table 2) and entered these values into a two-way ANOVA with Lexicality (two levels, word/pseudoword) and Repetition (three levels, first presentation, second presentation same, second presentation different) as within-subjects factors. There was no significant lexicality by priming interaction for any of the peak voxels that showed a lexicality effect (all $F<1$ ), although all voxels showed a main effect of lexicality and some voxels 
Table 2. Peak Voxels (Separated by $>8 \mathrm{~mm}$, in Clusters $>20$ Voxels) Activated for Words Compared to Pseudowords

\begin{tabular}{|c|c|c|c|c|c|}
\hline Location & Cluster Size & $Z$ & $x$ & $y$ & $z$ \\
\hline $\mathrm{L}$ anterior fusiform & 310 & 5.95 & -38 & -36 & -16 \\
\hline $\mathrm{L}$ angular gyrus & 1949 & 4.75 & -38 & -70 & 24 \\
\hline $\mathrm{L}$ angular gyrus & & 4.20 & -44 & -80 & 28 \\
\hline $\mathrm{L}$ inferior parietal & & 3.91 & -58 & -42 & 46 \\
\hline L middle occipital & & 3.84 & -32 & -82 & 36 \\
\hline L supramarginal gyrus & & 3.81 & -54 & -54 & 30 \\
\hline $\mathrm{L}$ inferior parietal & & 3.66 & -30 & -76 & 46 \\
\hline $\mathrm{L}$ inferior parietal & & 3.21 & -36 & -68 & 48 \\
\hline L middle frontal gyrus & 100 & 4.32 & -34 & 58 & 16 \\
\hline $\mathrm{R}$ precuneus & 2256 & 4.01 & 16 & -66 & 30 \\
\hline $\mathrm{R}$ precuneus & & 4.01 & 14 & -66 & 40 \\
\hline $\mathrm{R}$ posterior cingulate & & 3.87 & 8 & -32 & 46 \\
\hline L posterior cingulate & & 3.82 & -4 & -14 & 40 \\
\hline L precuneus & & 3.81 & -8 & -64 & 34 \\
\hline $\mathrm{R}$ precuneus & & 3.68 & 12 & -56 & 38 \\
\hline $\mathrm{R}$ precuneus & & 3.37 & -12 & -50 & 28 \\
\hline $\mathrm{R}$ angular gyrus & 507 & 3.88 & 42 & -72 & 20 \\
\hline $\mathrm{R}$ angular gyrus & & 3.61 & 34 & -82 & 36 \\
\hline $\mathrm{L}$ anterior insula & 39 & 3.81 & -22 & 26 & -16 \\
\hline $\mathrm{L}$ anterior insula & & 3.18 & -18 & 12 & -16 \\
\hline R orbitofrontal (medial) & 140 & 3.81 & 14 & 12 & -18 \\
\hline L IFG (pars orbitalis) & 41 & 3.74 & -36 & 42 & -12 \\
\hline $\mathrm{R}$ angular gyrus & 366 & 3.73 & 54 & -50 & 30 \\
\hline $\mathrm{R}$ posterior $\mathrm{MTG}$ & & 3.7 & 52 & -52 & 20 \\
\hline $\mathrm{L}$ anterior $\mathrm{MTG}$ & 49 & 3.65 & -56 & 0 & -20 \\
\hline L SFG & 46 & 3.62 & -16 & 44 & 10 \\
\hline L SFG & 83 & 3.57 & -6 & 38 & 32 \\
\hline L SFG & & 3.31 & -12 & 50 & 30 \\
\hline R SFG & 59 & 3.5 & 18 & 20 & 54 \\
\hline R Heschl's gyrus & 31 & 3.3 & 56 & -8 & 10 \\
\hline R Heschl's gyrus & & 3.22 & 54 & -2 & 16 \\
\hline R STG (middle) & 21 & 3.23 & 50 & -8 & -14 \\
\hline R STG (middle) & & 3.12 & 42 & -16 & -8 \\
\hline
\end{tabular}

All voxels, $p$ (uncorrected) $<.001$, and FDR, $p<.05$.

$\mathrm{IFG}=$ inferior frontal gyrus; $\mathrm{SFG}=$ superior frontal gyrus; $\mathrm{STG}=$ superior temporal gyrus.

showed robust priming effects. Equivalent results were obtained when second presentations with same and different voice repetitions were combined in these ANOVAs.
In the absence of any interaction between lexicality and priming, we therefore focus on those brain regions that showed changes in activity with repetition irrespective of the familiarity or otherwise of the stimuli (i.e., collapsed over word and pseudoword trials). Brain regions showing reduced activity for repeated versus first presentations included bilateral inferior frontal regions and a posterior inferior temporal area, as well as an area in the supplementary motor area (SMA, see Table 3, Figure 2B, and Figure 3B). In addition to this reduced BOLD response for repeated stimuli ("repetition suppression"), a number of regions showed the opposite response profile, a repetition-related increase in activation ("repetition enhancement"). These were dorsal frontal, orbitofrontal, and parietal regions bilaterally, the right posterior inferior temporal gyrus, and an area in the precuneus extending into the parietal lobe (see Table 4, Figure 2B, and Figure 3C). In a further analysis, we tested for anatomical overlap between effects of lexicality and priming, using the brain regions that showed a lexicality effect (words $>$ pseudowords, Figure $2 \mathrm{~B}$ ) as an ROI to detect further areas that showed a repetition priming effect (first $>$ second presentation, irrespective of lexicality). However, there was no overlap between these activations. Testing for a priming effect in each peak voxel that showed an effect of lexicality revealed that a peak voxel in the superior frontal gyrus showed a reliable priming effect $[-12+50+30, t(12)=$ $2.06, p<.05]$ in addition to the effect of lexicality, but no interaction between lexicality and priming.

\section{Relating Neural and Behavioral Priming Effects}

We observed several brain regions in which neural responses change with repetition. The question driving the next step of the analysis was which of the areas showing repetition suppression and enhancement are most closely associated with the behavioral facilitation observed in the lexical decision responses collected in the scanner. By looking for a more direct neural correlate of behavioral priming, we can establish which changes with repetition are central or epiphenomenal to priming. In a follow-up analysis, all second presentation trials were modeled, with the magnitude of behavioral priming entered as a covariate. The significance of this covariate was assessed within the brain regions that showed repetition suppression and enhancement in the initial analysis.

In this analysis, we assume that if a change in neural activity is directly related to behavioral priming, then changes with repetition (either suppression or enhancement) will be greater on trials that produce a larger behavioral priming effect. Within regions showing repetition suppression, we would therefore predict a negative correlation, such that neural responses to second presentations will show a greater reduction on trials that produced more behavioral priming. For each of the peak voxels that showed repetition suppression, we 
A
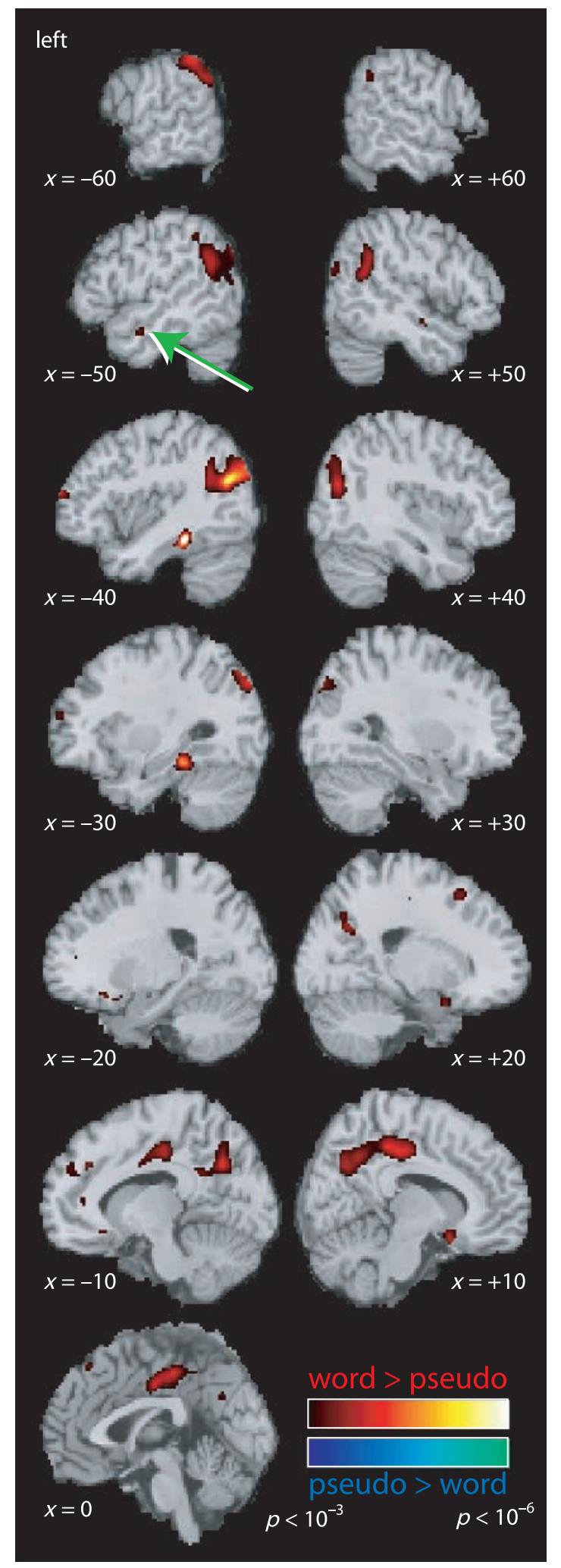

\section{B}

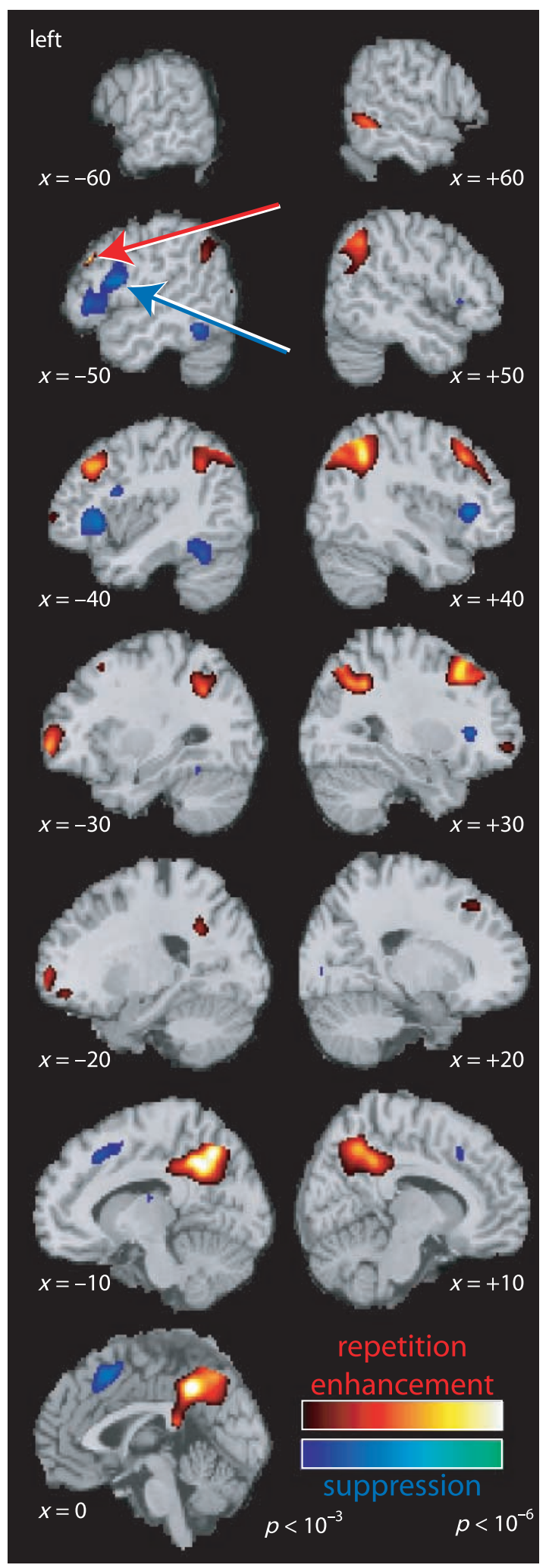

Figure 2. (A) Brain regions showing effects of lexicality displayed on the MNI standard brain, thresholded at $p<.001$ uncorrected (equivalent to $p<.05$ FDR). The green arrow indicates the approximate location of a voxel in the Middle Temporal Gyrus the response of which is plotted in Figure 3A. (B) Brain regions showing effects of repetition enhancement (red) and repetition suppression (blue), displayed as before. Arrows indicate voxels plotted in Figure 3B (red) and 3C (blue). 
Table 3. Peak Voxels (Separated by $>8 \mathrm{~mm}$, in Clusters $>20$ Voxels) That Showed Reduced Activation (Repetition Suppression) for the Second Presentation of an Item $[p$ (Uncorrected $)<.001$ and FDR $p<.05]$

\begin{tabular}{lccccc}
\hline Location & Cluster Size & $Z$ & $x$ & $y$ & $z$ \\
\hline L IFG (pars opercularis) & 815 & 4.09 & -46 & 14 & 18 \\
$\quad$ L IFG (pars triangularis) & & 4.02 & -46 & 30 & 4 \\
$\quad$ L precentral gyrus & & 3.44 & -56 & 10 & 36 \\
L posterior ITG & 412 & 3.96 & -46 & -46 & -12 \\
$\quad$ L cerebellum & & 3.82 & -44 & -56 & -28 \\
$\quad$ L fusiform & & 3.68 & -36 & -52 & -18 \\
R insula & 217 & 3.9 & 38 & 28 & 4 \\
SMA & 534 & 3.86 & 0 & 18 & 50 \\
$\quad$ L SMA & & 3.55 & -10 & 24 & 44 \\
R lingual gyrus & 27 & 3.66 & 26 & -82 & -2 \\
\hline
\end{tabular}

$\mathrm{IFG}=$ inferior frontal gyrus; SMA $=$ supplementary motor area; ITG $=$ inferior temporal gyrus.

therefore tested if the mean parameter relating neural and behavioral priming was less than zero. This comparison was significant for peak voxels in the left inferior frontal gyrus $[-56+10+36, t(12)=3.18, p<.005]$, in the left SMA $[-10+24+44, t(12)=2.04, p<.05]$, and in the right lingual gyrus $[+26,-82,-2, t(12)=$ $2.07, p<.05]$. These correlations between behavioral and neural priming are confirmed by a voxelwise analysis using the brain regions showing repetition suppression as an ROI (see Figure 4 and Table 5). In prefrontal regions and the SMA, activity on second presentations was significantly correlated with the magnitude of repetition priming for single trials at a corrected level of significance. This result suggests that behavioral priming is mediated by reductions in neural activity in these regions.

If repetition enhancement is similarly involved in modulating behavioral priming, we would predict an additional enhancement of the neural response to those second presentations that produced a larger behavioral priming effect. However, in contrast to our findings for repetition suppression, no significant positive correlation between priming and activation was observed in any of the peak voxels that showed repetition enhancement. No voxels in the ROI reached even an uncorrected threshold $(p<.05)$. This suggests that the dorsal frontal and posterior regions showing repetition enhancement do not directly contribute to behavioral priming. We will return to this point in the discussion.

\section{DISCUSSION}

The present behavioral and fMRI study investigated the systems responsible for spoken word recognition and

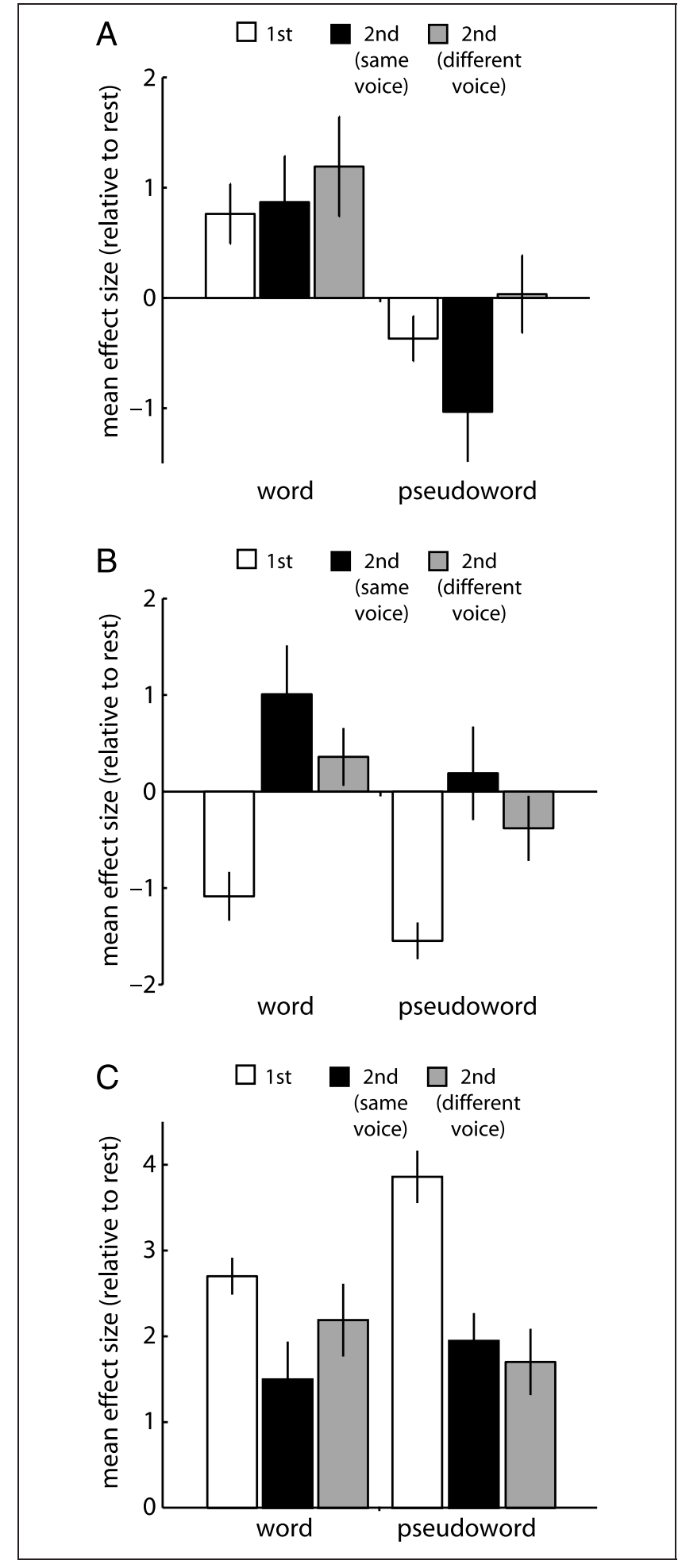

Figure 3. (A) Mean effect size (relative to rest) for responses to words and pseudowords (first and same- or different-voice second presentations) for a voxel in the anterior middle temporal gyrus $(-56,0,-20)$ marked with a green arrow in Figure 2A. Error bars show standard error of the mean after between-subject variance has been removed, suitable for repeated-measures comparisons (cf. Loftus and Masson, 1994). (B) Responses for a voxel in the left middle frontal gyrus $(-48,30,34)$ showing repetition enhancement, marked with a red arrow in Figure 2B. (C) Responses for a voxel in the left inferior frontal gyrus $(-48,14,18)$ showing repetition suppression, marked with a blue arrow in Figure $2 \mathrm{~B}$. 
Table 4. Peak Voxels (Separated by $>8 \mathrm{~mm}$, in Clusters $>20$ Voxels) That Showed Increased Activation (Repetition Enhancement) for the Second Presentation of an Item $[p$ (Uncorrected) $<.001$ and $\operatorname{FDR} p<.05]$

\begin{tabular}{|c|c|c|c|c|c|}
\hline Location & Cluster Size & $Z$ & $x$ & $y$ & $z$ \\
\hline Precuneus & 4471 & 5.16 & 0 & -46 & 42 \\
\hline $\mathrm{L}$ precuneus & & 5.09 & -12 & -62 & 46 \\
\hline $\mathrm{L}$ angular gyrus & & 4.58 & -34 & -54 & 38 \\
\hline L posterior cingulum & & 4.28 & -4 & -34 & 18 \\
\hline $\mathrm{L}$ inferior parietal & & 4.21 & -36 & -60 & 50 \\
\hline $\mathrm{L}$ angular gyrus & & 3.97 & -36 & -76 & 44 \\
\hline $\mathrm{L}$ angular gyrus & & 3.79 & -42 & -68 & 46 \\
\hline $\mathrm{L}$ inferior parietal & & 3.57 & -24 & -50 & 34 \\
\hline L middle frontal gyrus & 472 & 4.95 & -48 & 30 & 34 \\
\hline L middle frontal gyrus & & 3.49 & -34 & 20 & 52 \\
\hline $\mathrm{R}$ angular gyrus & 1835 & 4.94 & 34 & -52 & 38 \\
\hline $\mathrm{R}$ angular gyrus & & 4.68 & 34 & -62 & 38 \\
\hline $\mathrm{R}$ angular gyrus & & 4.41 & 34 & -68 & 48 \\
\hline $\mathrm{R}$ angular gyrus & & 3.43 & 56 & -64 & 22 \\
\hline $\mathrm{R}$ middle frontal gyrus & 1077 & 4.52 & 30 & 20 & 46 \\
\hline L orbitofrontal & 567 & 4.39 & -26 & 62 & -4 \\
\hline L orbitofrontal & & 3.45 & -20 & 48 & -10 \\
\hline $\mathrm{R}$ inferior temporal gyrus & 187 & 4.16 & 58 & -52 & -6 \\
\hline $\mathrm{R}$ orbitofrontal & 51 & 3.54 & 28 & 54 & -4 \\
\hline
\end{tabular}

how these systems are affected by same- and differentvoice repetitions of words and pseudowords during lexical decision. Our goal was to determine the neuroanatomical basis of the lexical representations of spoken
Table 5. Peak Voxels (Separated by $>8 \mathrm{~mm}$, in Clusters $>20$ Voxels) in Which Neural Response Suppression Correlated with Behavioral Priming within Regions Showing Repetition Suppression $[p$ (Uncorrected $)<.005$ and $p<.1$ FDR]

\begin{tabular}{lccccc}
\hline Location & Cluster Size & $Z$ & $x$ & $y$ & $z$ \\
\hline SMA & 129 & 3.11 & -4 & 4 & 54 \\
$\quad$ & & 3.08 & -8 & 10 & 46 \\
$\quad$ L SMA & & 2.70 & 6 & 10 & 52 \\
$\quad$ R SMA & & 3.06 & -36 & 32 & -10 \\
IFG (pars orbitalis) & 25 & 2.83 & -56 & 6 & 36 \\
Precentral gyrus & 27 & & & & \\
\hline
\end{tabular}

SMA $=$ supplementary motor area; $\mathrm{IFG}=$ inferior frontal gyrus

words and to assess theories in which either abstract phonological representations or episodic representations are responsible for repetition priming effects.

Behavioral data showed greater repetition priming for words than for pseudowords, although response facilitation for the pseudowords was still statistically significant. At the neural level, we found no evidence of the lexicality by priming interaction observed in behavior: Priming effects did not differ for words and pseudowords. Furthermore, changing the voice used for words and pseudowords on the second presentation had no significant effect on the magnitude of behavioral and neural repetition priming. Whereas a number of behavioral studies using other tasks have reported effects of voice change on the magnitude of priming, our results are in line with a previous study by Luce and Lyons (1998) that found no effect of voice change on auditory lexical decision. The null effect of voice change on neural repetition priming is also consistent with an earlier PET study by Badgaiyan et al. (2001) that found that same- and different-voice priming produced similar reductions in regional cerebral blood flow during an auditory stem completion task.

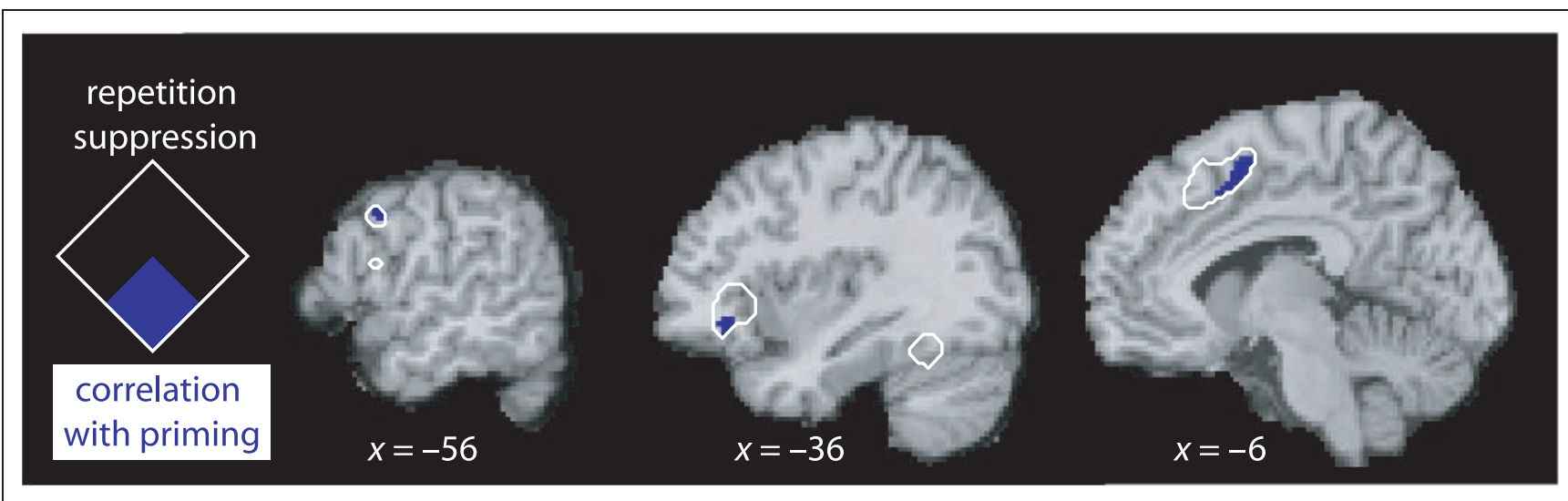

Figure 4. Brain regions showing a significant negative correlation between BOLD signal and the magnitude of priming (blue), thresholded at $p$ (uncorrected) $<.005$, within the region showing repetition suppression (white) at $p$ (uncorrected) $<.001$. 
The lack of a significant effect of changing the physical form of the stimuli between repetitions suggests that the representations being contacted in priming are at a more abstract level than an episodic trace consisting of all the physical properties of the stimulus item. However, because a repetition priming effect was observed for pseudowords as well as words, the results also present a problem for theories that claim that changes to abstract lexical representations are the locus of the repetition effect. Repetition priming for pseudowords that lack a preexisting memory representation, coupled with the voice change results, points toward a compromise position in which both the modification of preexisting representations and the acquisition of new representations can contribute to the priming effects. Real word priming can benefit from both components (Henson, 2003), whereas for pseudowords, recent behavioral evidence suggests that these two mechanisms can produce conflicting effects on lexical decision responses (episodic facilitation and familiarity-based inhibition; see Wagenmakers, Zeelenberg, Steyvers, Shiffrin, \& Raaijmakers, 2004; Zeelenberg, Wagenmakers, \& Shiffrin, 2004). We will consider in a later section what sort of mechanism is suggested by this pattern of priming.

\section{Responses to Words and Pseudowords}

A number of brain regions showed elevated activation for real words compared to pseudowords. There were three distinct loci in the left temporal lobe that showed this elevated response, all three of which were observed previously in a meta-analysis by Binder, Frost, Bellgowan, et al. (2000). We will initially focus on the posterior and anterior portion of the superior temporal gyrus (STG) because these areas correspond to the dorsal and ventral pathways in the macaque auditory system. Elevated activation for real words in the posterior STG and angular gyrus, as observed in the current study, confirms a number of earlier reports (Kotz, Cappa, von Cramon, \& Friederici, 2002; Price, Moore, Humphreys, \& Wise, 1997; Vandenberghe, Price, Wise, Josephs, \& Frackowiak, 1996; Demb et al., 1995; Kapur et al., 1994; Demonet et al., 1992; Petersen, Fox, Posner, Mintun, \& Raichle, 1988). Activation for real words compared to pseudowords in the anterior superior temporal sulcus is also consistent with a number of recent studies that measured neural responses for intelligible speech compared with temporally reversed speech (Crinion, Lambon-Ralph, Warburton, Howard, \& Wise, 2003), spectrally reversed speech (Scott, Blank, et al., 2000), or in a correlational design for a number of distortion types (Davis \& Johnsrude, 2003). In a recent study, Cohen, Jobert, Le Bihan, and Dehaene (2004) labeled this anterior temporal area an "auditory word form area" because it displayed repetition suppression for spoken words, although this was not observed in our work. The pattern of results that we observe in which re- sponses are observed in both anterior and posterior temporal regions is common to many recent fMRI studies using spoken stimuli. For instance, both Davis and Johnsrude (2003) and Narain et al. (2003) report both posterior and anterior temporal activation in fMRI studies assessing responses to sentences of varying intelligibility.

A third temporal lobe region in which an elevated response for real words was observed was an anterior region of the fusiform gyrus. Although frequently associated with visual processing of words, the inferior temporal region activated in this contrast is actually around $2 \mathrm{~cm}$ anterior to the visual word form area (Cohen, Jobert, et al., 2004; McCandliss, Cohen, \& Dehaene, 2003; Cohen, Lehericy, et al., 2002) and falls within a multimodal region of cortex (Price \& Devlin, 2003). Other studies have shown semantic activation in this region for experiments using words as stimuli. For instance, this region shows differences in activation for concrete and abstract nouns irrespective of modality of presentation (Fiebach \& Friederici, 2003; Wise et al., 2000). It is also activated during word reading by blind users of Braille (Buchel, Price, \& Friston, 1998), although in this case activation was not modulated by concreteness. These comparisons are relevant to the current study because in this work the real words presented were all concrete nouns. It may be that the activation observed in these (and other) regions reflect semantic processes that distinguish between real words and pseudowords. This observation is consistent with computational and neuropsychological investigations that propose that lexical decisions are computed using semantic information (see Rogers, Lambon Ralph, Hodges, \& Patterson, 2004; Gaskell \& Marslen-Wilson, 1997; Plaut, 1997). Consistent with this semantic hypothesis, we also observed elevated activation for real words in a rostral prefrontal region (Brodmann's area [BA] $9,-6+38+32)$ that has also been activated during other semantic tasks using word stimuli (Scott, Leff, \& Wise, 2003; Poldrack et al., 1999; Gabrieli, Poldrack, \& Desmond, 1998; Binder, Frost, Hammeke, et al., 1997). Finally, we observed a lexicality effect in a region of the middle frontal gyrus (BA 10/46, $-34+58+16$ ) previously associated with aspects of mnemonic retrieval and control (see, for instance, Simons \& Spiers, 2003). Consistent with a mnemonic interpretation of certain of these frontal activations, this region overlaps with an orbitofrontal region that shows repetition enhancement, a result that will be discussed in more detail in the next section.

On the basis of these results, it seems that neuroimaging contrasts between real and pseudowords are insufficient to distinguish the functional contributions of anterior and posterior temporal lobe systems; both seem to be engaged during the recognition of spoken words (see Scott \& Johnsrude, 2003; Hickok \& Poeppel, 2000, 2004, for relevant discussion). Evidence from 
neuropsychological studies with semantic dementia (Chan et al., 2001; Galton et al., 2001; Mummery et al., 1999) and aphasic stroke patients (Bates et al., 2003) suggest a role for both of these temporal lobe areas in lexical/semantic processing and are therefore similarly inconclusive. Thus, a variety of data suggests that both anterior and posterior temporal systems contribute to lexical/semantic processing. An important goal for future work is to functionally segregate these contributions (see Rodd, Davis, \& Johnsrude, 2005, for one such study).

There were no brain areas in this study that showed a significant reverse lexicality effect, that is, greater activation for pseudowords. This is despite behavioral results showing that lexical decision responses to pseudowords were slower and likely to be more effortful than responses to real words. The current results are in contrast to studies reporting elevated responses to pseudowords in lateral temporal regions. This could be due to methodological differences. Kotz et al. (2002), for instance, observed differential activation for words and pseudowords in the anterior and middle STG using a semantically primed auditory lexical decision task. This may reflect an attempt by participants in the Kotz et al. study to use the semantic prime as a cue to the meaning of a nonword. Newman and Twieg (2001), using the phoneme monitoring task, found an increase in activation for pseudoword processing in the left posterior STG, perhaps reflecting greater difficulty in phonological processing for nonwords. Further investigations comparing responses to nonwords in different task situations may be informative in this respect.

\section{Effects of Stimulus Repetition on Neural Responses}

In the present study, we observed two types of change as a consequence of repetition-repetition suppression (i.e., a reduced response to second presentations) and repetition enhancement (an increased response to second presentations). Unlike previous studies using visually presented words (Fiebach, Gruber, \& Supp, 2005), faces or symbols (Henson, Price, et al., 2002; Henson, Shallice, \& Dolan, 2000) these two profiles were observed consistently for both familiar and unfamiliar stimuli (words and pseudowords), but were observed in neuroanatomically distinct locations within frontal and posterior cortices.

One possible reason for the lack of word-specific priming effects in this study, in contrast to visual priming studies, lies in the nature of spoken word recognition. The recognition of spoken words entails processing a continuous input that is temporarily ambiguous at early points during recognition. Unlike written words, which are perceived in parallel (at least for short words), the speech signal is spread out in time such that for a substantial portion of the input it is not possible to distinguish words from pseudowords, or primed from unprimed items. This property of speech therefore suggests that representations activated at early time points during the recognition of spoken items will be equivalent for primed and unprimed words and pseudowords. Only once an appropriate representation has been activated can lexicality or priming effects (which may depend on the task being performed) come into play.

Although we know of no fMRI studies that directly compare long-term priming of words and pseudowords in the auditory and visual modalities, differences between auditory and visual word and pseudoword priming have been observed in behavioral studies. In particular, McKone and Dennis (2000) found that auditory repetition priming of lexical decision was longer lasting than visual priming, especially for nonwords. Intervening items reduced the priming effect for visually presented nonwords but not for auditory nonwords for which robust priming was still present after three intervening trials (about $8 \mathrm{sec}$ ), showing the same rate of decay as real words. Although these behavioral findings may not have direct implications for the BOLD priming effects measured in this study, they suggest that differences in the auditory and visual priming of words and nonwords could explain the differences between visual and auditory repetition suppression in fMRI.

The lag by lexicality interaction reported by McKone and Dennis (2000) also suggests a second possible explanation for the absence of a lexicality by priming interaction in the current study. Neuroimaging studies of repetition priming have reported significant reductions in the magnitude of priming effects as a function of the lag between first and second presentations, for faces and symbols (Henson, Rylands, Ross, Vuilleumeir, \& Rugg, 2004; Henson, Shallice, \& Dolan, 2000) and for words (Wagner, Koutsaal, et al., 2000), in areas such as the fusiform gyrus (although see van Turennout, Ellmore, \& Martin, 2000). Building on the suggestions of Henson, Rylands, et al. (2004), the discrepancies between results in our long-lag priming study and recent immediate priming studies (e.g., Cohen, Jobert, et al., 2004) might be a consequence of the delay that we introduced between first and second presentations. Two recent studies showing familiarity effects on face priming both used immediate repetition (Eger et al., 2005; Rothstein et al., 2004).

We observed repetition suppression for words and pseudowords in a number of brain regions previously associated both with lexical/semantic processing and response generation. In particular, we saw a reduced response to second presentations in inferolateral frontal regions of both hemispheres, in regions activated for a range of linguistic and nonlinguistic tasks (Duncan \& Owen, 2000). One unifying function proposed for these regions, which could explain both the priming profile observed in this task and a number of other studies of 
semantic processing (Buckner et al., 2000; ThompsonSchill, D'Esposito, \& Kan, 1999; Wagner, Desmond, Demb, Glover, \& Gabrieli, 1997), is that these frontal regions are engaged in response selection (Jiang \& Kanwisher, 2003; Schluter, Krams, Rushworth, \& Passingham, 2001; Schumacher \& D'Esposito, 2000; Rowe, Toni, Josephs, Frackowiak, \& Passingham, 2000). Our observation of repetition suppression in frontal and motor regions (such as the SMA) would be consistent with priming also having an effect on response generation and motor preparation processes. This is congruent with other observations of changes in premotor and motor cortical activity with increased practice at a task (Floyer-Lea \& Matthews, 2004; Jansma, Ramsey, Slagter, \& Kahn, 2001; Petersen, van Mier, Fiez, \& Raichle, 1998; Raichle et al., 1994). Other authors have similarly suggested a link between effects of practice and repetition priming (Poldrack \& Gabrieli, 2001; Logan, 1990).

We also saw significant repetition suppression in a region of the posterior fusiform gyrus in the left hemisphere. This activation overlaps with an area that showed cross-modal priming during word stem completion (Buckner et al., 2000), a finding that led these authors to propose that the posterior fusiform plays a role in the manipulation of lexical/semantic representations during stem completion. Our observation of equivalent repetition suppression for both words and pseudowords is difficult to reconcile with any strictly semantic role for this region. This result, coupled with the fact that this fusiform activation for spoken stimuli is very close to the fusiform region that has been described as a "visual word form area" (Cohen, Lehericy, et al., 2002; Fiebach, Friederici, Muller, \& von Cramon, 2002; Polk \& Farah, 2002), might suggest a more general role for this region (e.g., in phonological retrieval, Hillis et al., 2005; Price \& Devlin, 2003; Price, Winterburn, Giraud, Moore, \& Noppeney, 2003) as well as for generating visual form representations for written words. Recent work has proposed a gradation of function between posterior and anterior fusiform regions, corresponding to phonological and semantic processes in reading (Mechelli et al., 2005). On this basis, we therefore speculate that the repetition suppression effect observed in posterior fusiform may arise from repeated phonological processing of spoken materials, whereas the lexicality effect observed in more anterior regions arises from a semantic process that is unaffected by repetition.

In addition to these repetition suppression effects, we observed a number of brain regions in which second presentations of words and pseudowords evoked an enhanced response compared to first presentations. In particular, bilateral regions of the dorsolateral prefrontal cortex showed an elevated response to second presentations, as did a large, bilateral inferior parietal region, the precuneus and the right posterior inferior temporal cortex. ${ }^{1}$ Comparing this pattern of activation with that observed in studies of retrieval from episodic memory shows a striking degree of overlap with the neural regions that respond when subjects are instructed to explicitly distinguish old, studied items from novel, unstudied foils (Donaldson, Petersen, Ollinger, \& Buckner, 2001; for reviews, see Simons \& Spiers, 2003; Rugg \& Henson, 2002; Buckner \& Wheeler, 2001). This overlap in activation suggests that task situations in which repetition produces a behavioral priming effect also involve retrieval of episodic memories of prior encounters with those repeated stimuli.

Although priming effects in neuropsychological populations have been dissociated from episodic memory retrieval (Schachter \& Tulving, 1994; Squire \& Cohen, 1984; Warrington \& Weiskrantz, 1974), it remains unclear whether supposedly "implicit" measures of memory (such as behavioral priming) in healthy volunteers are uncontaminated by episodic influences. Behavioral investigations of spoken word priming show that episodic details of previous encounters with spoken words (such as the voice in which they are produced) can influence subsequent processing in certain tasks (Pilotti et al., 2000; Luce \& Pisoni, 1998; Goldinger, 1996). It is therefore critical to consider whether repetition effects observed in neuroimaging data are linked to the behavioral consequences of priming - that is, faster and more accurate responding.

The results of an analysis in which neural activity was correlated with the magnitude of behavioral priming on a trial-by-trial basis shows that repetition priming is more closely linked to prefrontal and motor systems involved in response selection and motor preparation than to systems involved in episodic retrieval. At a single-trial level, the magnitude of behavioral priming was best predicted by the degree of repetition suppression in the left inferior frontal gyrus and in the SMA. Thus, brain regions previously associated with aspects of response generation seem to be closely linked to our behavioral repetition priming effects. Similar results have also been obtained for the between-subject correlation of behavioral and neural priming for written words (Maccotta \& Buckner, 2004). Both these findings can be related to a recent proposal that repetition priming reflects rapid stimulus-response learning (Dobbins et al., 2004). In the behavioral priming literature, three lines of evidence provide support for this response learning interpretation. First, the priming effect is often specific to the task performed on the stimulus on its initial presentation (see Logan, 1990). Second, there are reports that priming effects increase as a function of the number of repetitions (Lewis \& Ellis, 1999; Brown, Jones, \& Mitchell, 1996; Grant \& Logan, 1993; Logan, 1988, 1990; Forbach, Stanners, \& Hochhaus, 1974; although see Scarborough, Cortese, \& Scarborough, 1977). Finally, in the context of studies such as ours, which show priming effects for both familiar and unfamiliar items, response learning is a plausible mechanism for generat- 
ing priming effects for pseudowords because stimulusresponse associations could still apply even if no preexisting lexical-semantic representation of a pseudoword exists.

Although we cannot draw strong conclusions from null findings in relating neural and behavioral effects, the absence of any correlation between priming and the robust repetition enhancement observed in brain regions associated with episodic retrieval at least challenges the idea that episodic memory plays a critical role in producing repetition priming. Just as neuropsychological evidence has suggested that patients with deficits in episodic memory can nonetheless show intact repetition priming, so neural activity in regions involved in episodic memory (such as the dorsolateral prefrontal cortex, inferior parietal regions and the precuneus) may be epiphenomenal to the behavioral priming that is observed in response times. Functional imaging techniques will show all the activity that is associated with stimulus presentation including processes that may not be necessarily involved in generating a response.

In summary, the present study confirms and extends findings on the role of the temporal lobe, both anterior and posterior, in the processing of spoken words. We show in a single study that both the anterior and posterior temporal areas identified in a meta-analysis of lexicality effects (Binder, Frost, Bellgowan, et al., 2000) show activity consistent with lexical/semantic processing of speech. However, to date, repetition priming has not provided a simple means by which we can determine the unique contribution of each of these regions to the recognition of familiar spoken words. Concerning the nature of the repetition priming effects, a parsimonious explanation of the results of the correlational analyses performed on the imaging data and of the repetition priming observed for pseudowords is that there is a component of the priming effect that reflects response learning (cf. Dobbins et al., 2004). However, the absence of voice effects on behavioral and neural priming suggests that even if priming is based on learnt responses for specific spoken items, these derive from abstract representations which exclude voice-specific information.

\section{Acknowledgments}

This work was supported by the Medical Research Council (UK). Eleni Orfanidou was also supported by the Leventis Foundation and the Cambridge European Trust. We thank Rik Henson, Ingrid Johnsrude, and two anonymous reviewers for comments and suggestions; the staff at the Wolfson Brain Imaging Center, University of Cambridge, for their help with data acquisition; and our volunteers for taking part.

Reprint requests should be sent to Matt Davis, Medical Research Council Cognition and Brain Sciences Unit, 15 Chaucer Road, Cambridge CB2 2EF, UK, or via e-mail: matt.davis@mrc-cbu. cam.ac.uk.
The data reported in this experiment have been deposited with the fMRI Data Center (www.fmridc.org). The accession number is 2-2006-121AR.

\section{Note}

1. As noted by an anonymous reviewer, it is of interest that repetition enhancement effect in posterior inferior temporal regions arises in a near-homologous region to the left inferior temporal region that shows repetition suppression. Although we are at a loss to explain this observation, we note that some visual priming studies with written words have reported differential repetition effects in left and right inferior temporal regions (e.g., Dehaene, Naccache, Ciuciu, et al., 2004; Dehaene, Naccache, Cohen, et al., 2001).

\section{REFERENCES}

Baayen, R. H., Piepenbrock., R., \& van Rijn, H. (1993). The CELEX lexical database [CD-ROM]. Linguistic data consortium. Philadelphia: University of Pennsylvania.

Badgaiyan, R. D., Schacter, D. L., \& Alpert, N. M. (2001). Priming within and across modalities: Exploring the nature of rCBF increases and decreases. Neuroimage, 13, 272-282.

Bates, E., Wilson, S. M., Saygin, A. P., Dick, F., Sereno, M. I., Knight, R. T., \& Dronkers, N. F. (2003). Voxel-based lesion symptom mapping. Nature Neuroscience, 6 , 448-450.

Bergerbest, D., Ghahremani, D. G., \& Gabrieli, J. D. E. (2004). Neural correlates of auditory repetition priming: Reduced fMRI activation in the auditory cortex. Journal of Cognitive Neuroscience, 16, 966-977.

Binder, J. R., Frost, J. A., Bellgowan, P. S. F., Springer, J. A., Kaufman, J. N., \& Posing, E. T. (2000). Human temporal lobe activation by speech and nonspeech sounds. Cerebral Cortex, 10, 512-528.

Binder, J. R., Frost, J. A., Hammeke, T. A., Cox, R. W., Rao, S. M., \& Pietro, T. (1997). Human brain language areas identified by functional MRI. Journal of Neuroscience, 17, 353-362.

Bowers, J. S. (1996). Different perceptual codes support priming for words and pseudowords: Was Morton right all along? Journal of Experimental Psychology: Learning, Memory, and Cognition, 22, 1336-1353.

Bowers, J. S. (2000). In defense of abstractionist theories of repetition priming and word identification. Psychonomic Bulletin and Review, 7, 83-99.

Brown, A. S., Jones, T. C., \& Mitchell, D. B. (1996). Single and multiple repetition priming in implicit memory. Memory, 4, 159-173.

Brown, J. S., \& Carr, T. H. (1993). Limits on perceptual abstraction in reading: Asymmetric transfer between surface forms differing in typicality. Journal of Experimental Psychology: Learning, Memory, and Cognition, 19, 1277-1296.

Buchel, C., Holmes, A. P., Rees, G., \& Friston, K. J. (1998). Characterizing stimulus-response functions using nonlinear regressors in parametric fMRI experiments. Neuroimage, 8, 140-148.

Buchel, C., Price, C., \& Friston, K. (1998). A multimodal region in the ventral visual pathway. Nature, 394, 274-277.

Buckner, R. L., Koutstaal, W., Schacter, D. L., \& Rosen, B. R. (2000). Functional MRI evidence for a role of frontal and inferior temporal cortex in amodal components of priming Brain, 123, 620-640. 
Buckner, R. L., \& Wheeler, M. E. (2001). The cognitive neuroscience of remembering. Nature Reviews Neuroscience, 2, 624-632.

Chan, D., Fox, N. C., Crum, W. R., Whitwell, J. L., Leschziner, G., Rossor, A. M., Stevens, J. M., Cipolotti, L., \& Rossor, M. N. (2001). Patterns of temporal lobe atrophy in semantic dementia and Alzheimer's disease. Annals of Neurology, 49, 433-442.

Church, B. A., \& Schacter, D. L. (1994). Perceptual specificity of auditory priming: Implicit memory for voice intonation. Journal of Experimental Psychology: Learning, Memory, and Cognition, 20, 521-533.

Cohen, L., Jobert, A., Le Bihan, D., \& Dehaene, S. (2004). Distinct unimodal and multimodal regions for word processing in the left temporal cortex. Neuroimage, 23, $1256-1270$.

Cohen, L., Lehericy, S., Chochon, F., Lemer, C., Rivaud, S., \& Dehaene, S. (2002). Language specific tuning of visual cortex? Functional properties of the visual word form area. Brain, 125, 1054-1069.

Crinion, J. T., Lambon-Ralph, M. A., Warburton, E. A., Howard, D., \& Wise, R. J. S. (2003). Temporal lobe regions engaged during normal speech comprehension. Brain, 126, 1193-1201.

Cusack, R., Brett, M., \& Osswald, K. (2003). An evaluation of the use of magnetic field maps to undistort echo-planar images. Neuroimage, 18, 127-142.

Davis, M. H., \& Johnsrude, I. S. (2003). Hierarchical processing in spoken language comprehension. Journal of Neuroscience, 23, 3423-3431.

Dehaene, S., Naccache, L., Ciuciu, P., Cohen, L., Poline, J. B., \& Cohen, L. (2004). Letter binding and invariant recognition of masked words-Behavioral and neuroimaging evidence. Psychological Science, 15, 307-313.

Dehaene, S., Naccache, L., Cohen, L., Bihan, D. L., Mangin, J. F., Poline, J. B., \& Riviere, D. (2001). Cerebral mechanisms of word masking and unconscious repetition priming. Nature Neuroscience, 4, 752-758.

Demb, J. B., Desmond, J. E., Wagner, A. D., Vaidya, C. J., Glover, G. H., Gabrieli, J. D. E. (1995). Semantic encoding and retrieval in the left inferior prefrontal cortex: A functional MRI study of task difficulty and process specificity. Journal of Neuroscience, 15, 5870-5878.

Demonet, J. F., Chollet, F., Ramsay, S., Cardebat, D., Nespoulous, J.-L., Wise, R., Rascol, A., \& Frackowiak, R. (1992). The anatomy of phonological and semantic processing in normal subjects. Brain, 115, 1753-1768.

Dobbins, I. G., Schnyer, D. M., Verfaellie, M., \& Schacter, D. L. (2004). Cortical activity reductions during repetition priming can result from response learning. Nature, 428, 316-319.

Donaldson, D. J., Petersen, S. E., Ollinger, J. M., \& Buckner, R. L. (2001). Separating state and item related processing during recognition memory using functional MRI. Neuroimage, 13, 129-142.

Duchek, J. M., \& Neely, J. H. (1989). A dissociative word frequency $\times$ levels of processing interaction in episodic recognition and lexical decision tasks. Memory and Cognition, 17, 148-162.

Duncan, J., \& Owen, A. M. (2000). Common regions of the human frontal lobe recruited by diverse cognitive demands. Trends in Neurosciences, 23, 475-483.

Eger, E., Schweinberger, S. R., Dolan, R. J., \& Henson, R. N. (2005) Familiarity enhances invariance of face representations in human ventral visual cortex: fMRI evidence. Neuroimage, 26, 1128-1139.

Feustel, T. C., Shiffrin, R. M., \& Salasoo, A. (1983). Episodic and lexical contributions to the repetition priming effect in word identification. Journal of Experimental Psychology: General, 112, 309-346.
Fiebach, C. J., \& Friederici, A. D. (2003). Processing concrete words: fMRI evidence against a specific right hemisphere involvement. Neuropsychologia, 42, 62-70.

Fiebach, C. J., Friederici, A. D., Muller, K., \& von Cramon, D. Y. (2002). fMRI evidence for dual routes to the mental lexicon. Journal of Cognitive Neuroscience, 14, 11-23.

Fiebach, C. J., Gruber, T., \& Supp, G. (2005). Neuronal mechanisms of repetition priming in occipito-temporal cortex: Spatiotemporal evidence from fMRI and EEG. Journal of Neuroscience, 25, 3414-3422.

Floyer-Lea, A., \& Matthews, P. M. (2004). Changing brain networks for visuomotor control with increased movement automaticity. Journal of Neurophysiology, 92, 2405-2412.

Forbach, G., Stanners, R., \& Hochhaus, L. (1974). Repetition and practice effects in a lexical decision task. Memory and Cognition, 2, 337-339.

Forster, K. L., \& Forster, J. C. (2003). DMDX: A windows display program with millisecond accuracy. Behavior Research Methods, Instruments, \& Computers, 35, 116-124.

Gabrieli, J. D. E., Poldrack, R. A., \& Desmond, J. E. (1998). The role of prefrontal cortex in language and memory. Cerebral Cortex, 95, 906-913.

Galton, C. J., Patterson, K., Graham, K., Lambon-Ralph, M. A., Williams, G., Antoun, N., Sahakian, B. J., \& Hodges, J. R. (2001). Differing patterns of temporal lobe atrophy in Alzheimer's disease and semantic dementia. Neurology, 57, 216-225.

Gaskell, G. M., \& Marslen-Wilson, W. D. (1997). Integrating form and meaning: A distributed model of speech perception. Language and Cognitive Processes, 12, 613-656.

Genovese, C. R., Lazar, N. A., \& Nichols, T. (2002). Thresholding of statistical maps in functional neuroimaging using the false discovery rate. Neuroimage, 15, 870-878.

Goldinger, S. D. (1996). Words and voices: Episodic traces in spoken word identification and recognition memory. Journal of Experimental Psychology: Learning, Memory, and Cognition, 22, 1166-1183.

Goldinger, S. D. (1998). Echoes of echoes? An episodic theory of lexical access. Psychological Review, 105, 251-279.

Grant, S. C., \& Logan, G. D. (1993). The loss of repetition priming and automaticity over time as a function of degree of initial learning. Memory and Cognition, 21, 611-618.

Grill-Spector, K., Kushnir, T., Edelman, S., Avidan, G., Itzchak, Y., \& Malach, R. (1999). Differential processing of objects under various viewing conditions in the human lateral occipital complex. Neuron, 24, 187-203.

Henson, R. N. A. (2003). Neuroimaging studies of priming. Progress in Neurobiology, 70, 53-81.

Henson, R. N. A., Rylands, A., Ross, E., Vuilleumeir, P., \& Rugg, M. D. (2004). The effect of repetition lag on electrophysiological and haemodynamic correlates of visual object priming. Neuroimage, 21, 1674-1689.

Henson, R. N. A., Shallice, T., \& Dolan, R. (2000). Neuroimaging evidence for dissociable forms of priming. Science, 287, 1269-1272.

Henson, R. N. A., Shallice, T., Gorno-Tempini, M.-L., \& Dolan, R. J. (2002). Face repetition effects in implicit and explicit memory tests as measured by fMRI. Cerebral Cortex, 12, 178-186.

Hickok, G., \& Poeppel, D. (2000). Towards a functional neuroanatomy of speech perception. Trends in Cognitive Sciences, 4, 131-138.

Hickok, G., \& Poeppel, D. (2004). Dorsal and ventral streams: A framework for understanding aspects of the functional anatomy of language. Cognition, 92, 67-99.

Hillis, A. E., Newhart, M., Heidler, J., Barker, P., Herskovits, E., \& Degaonkar, M. (2005). The roles of the "visual word form area" in reading. Neuroimage, 24, 548-559. 
James, T. W., Humphrey, G. K., Gati, J. S., Menon, R. S., \& Goodale, M. A. (2002). Differential effects of viewpoint on object driven activation in dorsal and ventral streams. Neuron, 793-801.

Jansma, J. M., Ramsey, N. F., Slagter, H. A., \& Kahn, R. S. (2001). Functional anatomical correlates of controlled and automatic processing. Journal of Cognitive Neuroscience, 13, 730-743.

Jiang, Y., \& Kanwisher, N. (2003). Common neural substrates for response selection across modalities and mapping paradigms. Journal of Cognitive Neuroscience, 15 , 1080-1094.

Josephs, O., \& Henson, R. N. A. (1999). Event-related fMRI: Modelling, inference and optimization. Philosophical Transactions of the Royal Society of London, Series B, Biological Sciences, 354, 1215-1228.

Kaas, J., \& Hackett, T. (2000). Subdivisions of auditory cortex and processing streams in primates. Proceedings of the National Academy of Sciences, U.S.A., 97, 11793-11799.

Kapur, S., Rose, R., Liddle, P. F., Zipursky, R. B., Brown, G. M., Stuss, D., Houle, S., \& Tulving, E. (1994). The role of prefrontal cortex in verbal processing: Semantic processing or willed action? NeuroReport, 5, 2193-2196.

Kotz, S. A., Cappa, S. F., von Cramon, D. Y., \& Friederici, A. D. (2002). Modulation of the lexical-semantic network by auditory semantic priming: An event-related functional MRI study. Neuroimage, 17, 1761-1772.

Kourtzi, Z., \& Kanwisher, N. (2000). Cortical regions involved in perceiving object shape. Journal of Neuroscience, 20, 3310-3318.

Koutsaal, W., Wagner, A. D., Rotte, M., Maril, A., Buckner, R. L., \& Schacter, D. L. (2001). Perceptual specificity in visual object priming: Functional magnetic resonance imaging evidence for a laterality difference in fusiform cortex. Neuropsychologia, 39, 184-199.

Lewis, M. B., \& Ellis, H. D. (1999). Repeated repetition priming in face recognition. The Quarterly Journal of Experimental Psychology, 52A, 927-955.

Loftus, G. R., \& Masson, M. E. J. (1994). Using confidenceintervals in within-subject designs. Psychonomic Bulletin and Review, 1, 476-490.

Logan, G. D. (1988). Towards an instance theory of automatization. Psychological Review, 95, 492-527.

Logan, G. D. (1990). Repetition priming and automaticity: Common underlying mechanisms? Cognitive Psychology, 22, $1-35$.

Luce, P. A., \& Lyons, E. A. (1998). Specificity of memory representation for spoken words. Memory and Cognition, 26, 708-715.

Luce, P. A., \& Pisoni, D. B. (1998). Recognizing spoken words: The neighborhood activation model. Ear and Hearing, 19, 1-36.

Maccotta, L., \& Buckner, R. L. (2004). Evidence for neural effects of repetition that directly correlate with behavioral priming. Journal of Cognitive Neuroscience, 16, 1625-1632.

McCandliss, A., Cohen, L., \& Dehaene, S. (2003). The visual wordform area: Expertise for reading in the fusiform gyrus. Trends in Cognitive Sciences, 7, 293-299.

McKone, E., \& Dennis, C. (2000). Short-term implicit memory: Visual, auditory, and cross-modality priming. Psychonomic Bulletin and Review, 7, 341-346.

McLennan, C. T., \& Luce, P. A. (2005). Examining the time course of indexical specificity effects in spoken word recognition. Journal of Experimental Psychology: Learning, Memory, and Cognition, 31, 206-321.

Mechelli, A., Crinion, J. T., Lond, S., Friston, K. J., Lambon-Ralph, M. A., Patterson, K., McClelland, J. L., \& Price, C. J. (2005). Dissociating reading processes on the basis of neuronal interactions. Journal of Cognitive Neuroscience, 17, 1753-1765.

Mimura, M., Verfaellie, M., \& Milberg, W. P. (1997). Repetition priming in an auditory lexical decision task: Effects of lexical status. Memory and Cognition, 25, 819-825.

Mummery, C. J., Patterson, K., Wise, R. J. S., Vandenbergh, R., Price, C. J., \& Hodges, J. R. (1999). Disrupted temporal lobe connections in semantic dementia. Brain, 122, 61-73.

Narain, C., Scott, S. K., Wise, R. J. S., Rosen, S., Leff, A., Iversen, S. D., \& Matthews, P. M. (2003). Defining a left-latelarized response specific to intelligible speech using fMRI. Cerebral Cortex, 13, 1362-1368.

Newman, S. D., \& Twieg, D. (2001). Differences in auditory processing of words and pseudowords: An fMRI study. Human Brain Mapping, 14, 39-47.

Norris, D. (1994). Shortlist: A connectionist model of continuous speech recognition. Cognition, 52, 189-234.

Palmeri, T. J., Goldinger, S. D., \& Pisoni, D. B. (1993). Episodic encoding of voice attributes and recognition memory. Journal of Experimental Psychology: Learning, Memory, and Cognition, 19, 309-328.

Petersen, S. E., Fox, P. T., Posner, M. I., Mintun, M., \& Raichle, M. E. (1988). Positron emission tomographic studies of the processing of single-words. Journal of Cognitive Neuroscience, 1, 153-170.

Petersen, S. E., van Mier, H., Fiez, J. A., \& Raichle, M. E. (1998). The effects of practice on functional anatomy of task performance. Proceedings of the National Academy of Sciences, U.S.A., 95, 853-860.

Pilotti, M., Bergman, E. T., Gallo, D. A., Sommers, M., \& Roediger, H. L., III. (2000). Direct comparison of auditory implicit memory tests. Psychonomic Bulletin and Review, 7, 347-353.

Plaut, D. C. (1997). Structure and function in the lexical system: Insights from distributed models of word reading and lexical decision. Language and Cognitive Processes, 12, 767-808.

Poldrack, R. A., \& Gabrieli, J. D. (2001). Characterizing the neural mechanisms of skill learning and repetition priming. Brain, 124, 67-82.

Poldrack, R. A., Wagner, A. D., Prull, M. W., Desmond, J. E., Glover, G. H., \& Gabrieli, J. D. E. (1999). Functional specialization for semantic and phonological processing in the left inferior prefrontal cortex. Neuroimage, 10, 15-35.

Polk, T. A., \& Farah, M. J. (2002). Functional MRI evidence for an abstract, not perceptual, word-form area. Journal of Experimental Psychology: General, 131, 65-72.

Price, C. J., \& Devlin, J. T. (2003). The myth of the visual word form area. Neuroimage, 19, 473-481.

Price, C. J., Moore, C. J., Humphreys, G. W., \& Wise, R. J. S. (1997). Segregating semantic from phonological processes during reading. Journal of Cognitive Neuroscience, 9, 727-733.

Price, C. J., Winterburn, D., Giraud, A. L., Moore, C. J., \& Noppeney, U. (2003). Cortical localisation of the visual and auditory word form areas: A reconsideration of the evidence. Brain and Language, 86, 272-286.

Raaijmakers, J. G. W., Schrijnemakers, J. M. C., \& Gremmen, F. (1999). How to deal with "The language-as-fixed-effect fallacy": Common misconceptions and alternative solutions. Journal of Memory and Language, 41, 416-426.

Raichle, M. E., Fiez, J. E., Videen, T. O., MacLeod, A. M., Pardo, J. V., Fox, P. T., \& Petersen, S. E. (1994). Practice-related changes in human brain functional anatomy during non-motor learning. Cerebral Cortex, 4, 8-26.

Ratcliff, R., Hockley, W., \& McKoon, G. (1985). Components of activation: Repetition and priming effects in lexical 
decision and recognition. Journal of Experimental Psychology: General, 114, 435-450.

Rauschecker, J. P. (1998). Parallel processing in the auditory cortex of primates. Audiological Neuroontology, 3, 86-103.

Rauschecker, J. P., \& Tian, B. (2000). Mechanisms and streams for processing of 'what' and 'where' in auditory cortex. Proceedings of the National Academy of Sciences, U.S.A., 97, 11800-11806.

Rodd, J., Davis, M. H., \& Johnsrude, I. S. (2005). Neural mechanisms of speech comprehension: fMRI studies of semantic ambiguity. Cerebral Cortex, 15, 1261-1269.

Rogers, T. T., Lambon Ralph, M. A., Hodges, J. R., \& Patterson, K. (2004). Natural selection: The impact of semantic impairment on lexical decision and object decision. Cognitive Neuropsychology, 21, 331-352.

Romanski, L. M., Tian, B., Fritz, J., Mishkin, M., Goldman-Rakic, P. S., \& Rauschecker, J. P. (1999). Dual streams of auditory afferents target multiple domains in the primate prefrontal cortex. Nature Neuroscience, 2, $1131-1136$

Rothstein, P., Henson, R. N. A., Treves, A., Driver, J., \& Dolan, R. J. (2004). Morphing Marilyn into Maggie dissociates physical and identity face representations in the brain. Nature Neuroscience, 8, 107-113.

Rowe, J. B., Toni, I., Josephs, O., Frackowiak, R. S. J., \& Passingham, R. E. (2000). The prefrontal cortex: Response selection or maintenance within working memory? Science, 288, 1656-1660.

Rueckl, J. G. (1990). Similarity effects in word and pseudoword repetition priming. Journal of Experimental Psychology: Learning, Memory, and Cognition, 16, 374-391.

Rugg, M. D., \& Henson, R. N. A. (2002). Episodic memory retrieval: An (event-related) functional neuroimaging perspective. In A. Parker, E. Wilding, \& T. Bussey (Eds.), The cognitive neuroscience of memory: Encoding and retrieval (pp. 3-37). Hove, UK: Psychology Press.

Scarborough, D. L., Cortese, C., \& Scarborough, H. S. (1977). Frequency and repetition effects in lexical memory. Journal of Experimental Psychology: Human Perception and Performance, 3, 1-17.

Schacter, D. L., \& Buckner, R. L. (1998). Priming and the brain. Neuron, 20, 185-195.

Schacter, D. L., \& Church, B. A. (1992). Auditory priming and explicit memory for words and voices. Journal of Experimental Psychology: Learning, Memory, and Cognition, 18, 915-930.

Schacter, D. L., \& Tulving, E. (1994). Memory systems. Cambridge, MA: MIT press.

Schluter, N. D., Krams, M., Rushworth, M. F., \& Passingham, R. (2001). Cerebral dominance for action in the human brain: The selection of actions. Neuropsychologia, 39, 105-113.

Schumacher, E. H., \& D'Esposito, M. (2000). Neural implementation of response selection in humans as revealed by localised effects of stimulus-response compatibility on brain activation. Human Brain Mapping, 17, 193-201.

Scott, S. K., Blank, C. C., Rosen, S., \& Wise, R. J. S. (2000). Identification of a pathway for intelligible speech in the left temporal lobe. Brain, 123, 2400-2406.

Scott, S. K., \& Johnsrude, I. S. (2003). The neuroanatomical and functional organization of speech perception. Trends in Neurosciences, 26, 100-107.
Scott, S. K., Leff, A. P., \& Wise, R. J. S. (2003). Going beyond the information given: A neural system supporting semantic interpretation. Neuroimage, 19, 870-876.

Sheffert, S. M. (1998). Voice-specificity effects on auditory priming. Memory and Cognition, 26, 591-598.

Simons, J. S., \& Spiers, H. J. (2003). Prefrontal and medial temporal interactions in long-term memory. Nature Reviews Neuroscience, 4, 637-648.

Squire, L., \& Cohen, N. J. (1984). Human memory and amnesia. In G. L. L. McGaugh \& N. M. Weinberger (Eds.), The neurobiology of learning and memory (pp. 3-64). New York: Guilford Press.

Tenpenny, P. L. (1995). Abstractionist versus episodic theories of repetition priming. Psychonomic Bulletin and Review, 2, 339-263.

Thompson-Schill, S. L., D'Esposito, M., \& Kan, I. P. (1999). Effects of repetition and competition on activity in left prefrontal cortex during word generation. Neuron, 23, $513-522$.

Ungerleider, L. G., \& Mishkin, M. (1982). Two cortical visual systems. In D. J. Ingle, M. A. Goodale, \& R. J. W. Mansfield (Eds.), Analysis of visual behavior (pp. 549-586). Cambridge: MIT Press.

van Turennout, M., Ellmore, T., \& Martin, A. (2000). Long-lasting cortical plasticity in the object naming system. Nature Neuroscience, 3, 1329-1334.

Vandenberghe, R., Price, C., Wise, R., Josephs, O., \& Frackowiak, R. S. J. (1996). Functional anatomy of a common semantic system for words and pictures. Nature, 383, 254-256.

Vuilleumier, P., Henson, R. N., Driver, J., \& Dolan, R. J. (2002). Multiple levels of object constancy revealed by event-related fMRI of repetition priming. Nature Neuroscience, 5, 491-499.

Wagenmakers, E. J. M., Zeelenberg, R., Steyvers, M., Shiffrin, R., \& Raaijmakers, J. G. W. (2004). Nonword repetition in lexical decision: Support for two opposing processes. Quarterly Journal of Experimental Psychology, Series A, Human Experimental Psychology, 57, 1191-1210.

Wagner, A. D., Desmond, J. E., Demb, J. B., Glover, G. H., \& Gabrieli, J. D. E. (1997). Semantic repetition priming for verbal and pictorial knowledge: A functional MRI study of left inferior prefrontal cortex. Journal of Cognitive Neuroscience, 9, 714-726.

Wagner, A. D., Koutsaal, W., Maril, A., Schacter, D. L., \& Buckner, R. L. (2000). Task-specific repetition priming in left inferior prefrontal cortex. Cerebral Cortex, 10, 1176-1184.

Warrington, E. K., \& Weiskrantz, L. (1974). The effects of prior learning on subsequent repetition in amnesic patients. Neuropsychologia, 12, 419-428.

Wise, R. J. S., Howard, D., Mummery, C. J., Fletcher, P., Leff, A., \& Buchel, C. (2000). Noun imageability and the temporal lobes. Neuropsychologia, 38, 985-994.

Xiong, J., Rao, S., Jerabek, P., Zamarripa, F., Woldorff, M. Lancaster, J., \& Fox, P. T. (2000). Intersubject variability in cortical activations during a complex language task. Neuroimage, 12, 326-339.

Zeelenberg, R., Wagenmakers, E., \& Shiffrin, R. M. (2004). Nonword repetition priming in lexical decision reverses as a function of study task and speed stress. Journal of Experimental Psychology: Learning, Memory, and Cognition, 30, 270-277. 